\title{
A vivência do cuidador familiar de vítima de Acidente Vascular Encefálico: uma abordagem interacionista*
}

\author{
The experience of the family caregiver of stroke victim: an interactionist approach
}

La vivencia del cuidador familiar de víctima de Accidente Vascular Encefalico: un abordaje interaccionista

\author{
Ana Larissa Gomes Machado', Maria Salete Bessa Jorge', Consuelo Helena Aires Freitas \\ 'Universidade Estadual de do Ceará. Departamento de Enfermagem. Curso de Mestrado. Fortaleza, CE
}

Submissão: 16/09/2008

Aprovação: $31 / 12 / 2008$

\section{RESUMO}

Esta pesquisa Qualitativa teve como objetivo compreender a vivência do cuidador familiar no processo de cuidar de pessoas incapacitadas por AVE, no contexto domiciliar. Foi realizada no Programa de Assistência Domiciliária de um hospital público terciário de Fortaleza$\mathrm{CE}$, com nove cuidadores. Os depoimentos foram obtidos por meio de entrevistas gravadas e organizados em categorias, posteriormente interpretadas à luz do Interacionismo Simbólico: por que eu cuido?, percebendo o familiar vitimado pelo AVE, as atividades diárias dos cuidadores, percebendo-se cuidador e as transformações nas vidas dos cuidadores. A análise realizada sugere Que o profissional introduza em seu cuidado instrumentos Que facilitem o processo de adaptação da família à nova situação, como a sensibilidade para promover a capacitação dos cuidadores familiares.

Descritores: Cuidadores; Assistência domiciliar; Enfermagem familiar.

\begin{abstract}
This Qualitative research aimed at understanding the experience of familiar caregivers in the process of caring for persons disabled by stroke, in their home. It was held in the Program of Domiciliary Assistance of a tertiary public hospital in Fortaleza-CE, with nine caregivers. The statements were obtained through interviews recorded and organized into categories, then interpreted according to the Symbolic Interactionism method: why I take care?, Realizing the family victimized by stroke, the daily activities of caregivers, perceiving themselves as caregivers and the changes in the lives of caregivers. The analysis suggests that the nurse insert into its care tools that facilitate the process of adaptation to the new situation of the family, such as sensitivity to promote the training of familiar caregivers.

Descriptors: Caregivers; Home care; Familiar nursing.
\end{abstract}

\section{RESUMEN}

Esta investigación tuvo como objetivo comprender la vivencia del cuidador familiar en el proceso de cuidar de personas incapacitadas por AVE, en el contexto domiciliar. Fue realizada en el Programa de Asistencia Domiciliar (PAD) de un hospital público terciario de Fortaleza-CE, con nueve cuidadores. Las declaraciones se obtuvieron por medio de entrevistas grabadas y organizados en categorías, posteriormente interpretadas a la luz del Interaccionismo Simbólico: ¿por Qué cuido?, percibiendo al familiar victimado por el AVE, las actividades diarias de los cuidadores, percibiéndose cuidador y las transformaciones en las vidas de los cuidadores. El análisis realizado sugiere al enfermero Que introduzca en su cuidado instrumentos que faciliten el proceso de adaptación de la familia a la nueva situación, como la sensibilidad para promover la capacitación de los cuidadores familiares.

Descriptores: Cuidadores; Asistencia domiciliar; Enfermería familiar. 


\section{INTRODUÇÃO}

O fenômeno de transição epidemiológica observado no País, caracterizado pela redução de mortes por doenças infecciosas e pelo concomitante aumento das mortes por doenças crônicas nãotransmissíveis e causas externas, tem impactos diretos sobre o indivíduo, sua família e sociedade ${ }^{(1)}$.

Entre os anos de 1991 e 1998 houve aumento na taxa de mortalidade por doenças do aparelho circulatório em todas as regiões brasileiras e entre 1996 e 2000 as doenças cardiovasculares (DCV) apareceram como a segunda principal causa de morbidade hospitalar, excluindo-se gravidez, parto e puerpério(2).

As elevadas taxas de mortalidade relacionadas às doenças do sistema cardiovascular têm como fatores colaboradores os déficits funcionais e cognitivos Que delas decorrem. Os acidentes cerebrovasculares, por exemplo, geram incapacidades, como a perda do controle voluntário dos movimentos musculares, problemas sensoriais, incontinência, e problemas na comunicação e na fala, Que comprometem a saúde física, emocional e social de uma pessoa $^{(3)}$.

O termo Acidente Vascular Encefálico (AVE) refere-se à redução súbita da circulação cerebral em um ou mais vasos sanguíneos ${ }^{(4)}$. As implicações Que dele decorrem envolvem além da mortalidade, um grande impacto econômico, em virtude das seqüelas neurológicas provocadas nos pacientes.

É cada vez mais comum o manejo das incapacidades geradas pela doença no contexto familiar. Vários estudos reforçam o importante papel da família como determinante nos resultados do processo de reabilitação ${ }^{(5-7)}$. Diante de tal fato, os enfermeiros são chamados a interagir com os membros familiares e, para isso, devem pautar seus cuidados para além da orientação de normas de vida.

Torna-se necessário incorporar à prática clínica cuidados aos sujeitos Que irão possibilitar o tratamento fora do contexto hospitalar. O acompanhamento domiciliário de uma pessoa com incapacidades geradas pelo AVE envolve o ensino e a capacitação dos cuidadores familiares, uma vez Que esses indivíduos são partícipes do processo de cuidar.

$\mathrm{Na}$ relação entre o enfermeiro e o cuidador familiar deve-se fazer presente um espaço de educação, no Qual a assistência seja feita por meio de um trabalho educativo instrumentalizado por saberes e técnicas Que visem a proximidade física, a criatividade, o respeito pelos costumes e culturas e o preparo da família para assumir os cuidados com a saúde do ser enfermo.

Nessa perspectiva, o cuidado acontece durante a interação com o outro, ou seja, aquele Que cuida deve mostrar-se capaz de compreender o outro em seu mundo de vida e, dessa forma, potencializar a sua capacidade para o enfrentamento de problemas a partir dos significados, conceitos e crenças Que possui ${ }^{(8)}$.

As ações do cuidador familiar são, portanto, mediadas por significados. Para a compreensão dos mesmos, são necessários o diálogo, Que permitirá a verbalização daQuilo Que realmente tem significado para o cuidador, e a observação nos momentos em Que o mesmo age, ou seja, cuida.

Para a compreensão dos significados advindos das vivências dos familiares no processo de cuidar, utilizou-se, neste estudo, a teoria do Interacionismo Simbólico ${ }^{(8)}$, uma vez Que traz conceitos importantes para o estudo do ser humano como ser social.
Aponta-se, portanto, como objetivo do presente estudo: compreender a vivência do cuidador familiar no processo de cuidar de pessoas incapacitadas por AVE, no contexto domiciliar.

\section{Referencial Teórico-Metodológico}

Optou-se pelo interacionismo simbólico, considerando Que a teoria tem como objetivo compreender a causa da ação humana, transformada de maneira Que a definição dada pelo indivíduo tenha significado e, portanto, autodireção e escolhas sobre as situações ${ }^{(9)}$.

O termo interacionismo simbólico é usado como denominação para uma abordagem relativamente descritiva do estudo do grupo e da vida humana. A obra célebre da teoria interacionista explora a relação complexa entre o indivíduo e a sociedade e aborda o processo de comportamento da mente humana ${ }^{(10)}$.

Entre os conceitos trazidos pela teoria destacam-se a mente, entendida como a capacidade humana de vivenciar experiências interiores e refletir sobre sua condição, o self (eu), compreendido como o aspecto espontâneo e impulsivo do ser humano, muitas vezes controlado por padrões sociais, e a sociedade, constituída por grupos de pessoas ou animais Que estabelecem relações e interações $^{(1)}$.

Os princípios interacionistas adotados nesse estudo foram: o pesquisador deve fazer uso de algum Quadro prévio de referência ou esQuema do mundo empírico em estudo, elaborar interrogações sobre o mundo empírico em estudo, determinar os dados a serem coletados e os meios pelos Quais serão coletados, interpretar os resultados obtidos a partir do referencial teórico e, por fim, deve conceituar o Que foi descoberto ${ }^{(8)}$.

O seguimento dos princípios metodológicos interacionistas e a observação direta do "mundo da realidade" dos cuidadores familiares forneceram informações as Quais permitiram a compreensão de sua vivência no cuidado ao vitimado por AVE.

\section{METODOLOGIA}

Pesquisa de natureza Qualitativa desenvolvida no período de maio a setembro de 2007, em dois contextos distintos: Programa de Assistência Domiciliar (PAD) e domicílios.

O PAD pertence a um hospital público terciário do município de Fortaleza/CE. Os serviços oferecidos à comunidade são: fornecimento de material médico-hospitalar (pacote contendo material para curativos e sondas de aspiração), medicação padronizada do hospital, cama hospitalar e suporte nutricional enteral (frascos, equipos e seringas), marcação de consultas especializadas, coleta de exames laboratoriais no domicílio e capacitação de cuidadores domiciliares leigos para prestar cuidados à saúde na residência.

Uma vez cadastrados, os pacientes contam com o apoio da equipe multidisciplinar que insere os cuidadores familiares nas dinâmicas das atividades educacionais para Que eles participem ativamente das atividades de cuidado desenvolvidas nas residências.

A observação das atividades realizadas em domicílio, segundo campo de investigação, permitiu a plena interação com os cuidadores. Além disso, revelou as características das famílias, seus hábitos e distintos modos de cuidar.

Participaram da pesquisa 09 cuidadores familiares de ambos os sexos, identificados pela letra $\mathrm{C}$, selecionados a partir dos critérios: 
ser cuidador de pessoa incapacitada por AVC e ter recebido em sua residência o familiar incapacitado há pelo menos 30 dias.

A seleção do número de participantes do estudo foi definida a partir da observação do fluxo de pacientes no PAD a cada mês, seguindo-se os critérios de inclusão estabelecidos e após anuência dos participantes por meio de termo de consentimento livre e esclarecido.

A coleta dos dados ocorreu a partir da observação participante e de entrevista semi-estruturada sobre os significados dos cuidadores acerca da atenção domiciliário. Para a observação participante, seguiu-se um roteiro, utilizado no PAD, e anotações em diário de campo, resultantes das observações em domicílio.

Os dados obtidos a partir das entrevistas foram organizados a partir da técnica de análise temática ${ }^{(12)}$. Após a leitura e a organização dos resultados, utilizou-se o referencial teórico do interacionismo simbólico para a fase de interpretação.

O estudo foi analisado e aprovado pelo Comitê de Ética em Pesquisa da instituição hospitalar no Qual foi desenvolvido, parecer CEP de número $110406 / 07$, por estar em conformidade com a Resolução 196/96 do Conselho Nacional de Saúde $(\mathrm{CNS})^{(13)}$.

\section{RESULTADOS E DISCUSSÃO}

A compreensão dos significados atribuídos à experiência de cuidar deu-se a partir da construção do tema: a vivência do cuidador familiar. O mesmo será descrito segundo os modos de pensar e de agir dos participantes do estudo.

\section{A vivência do cuidador familiar}

Retrata os aspectos considerados significativos pelo cuidador. Traz suas motivações para o cuidado, impressões acerca de si mesmo e da pessoa Que ele cuida e o impacto de suas atividades na própria vida. Esse tema é formado pelas categorias temáticas: por Que eu cuido? (A), percebendo o familiar vitimado pelo AVE (B), as atividades diárias dos cuidadores $(\mathrm{C})$, percebendo-se cuidador (D) e as transformações nas vidas dos cuidadores (E).

\section{Por Que eu cuido?}

Revela as motivações para a assunção da função de cuidador. Inicialmente aparecem como grandes motivos os papéis do pai e da mãe dentro do grupo social.

Para os cuidadores cujos pais eram os elementos da família Que estavam doentes, realizar atividades de cuidado determinava-se por uma composição de sentimentos. Entre os mais destacados estão o cuidado como obrigação e o cuidado por amor.

\section{O Cuidado Como Obrigação}

É muito importante por ser minha mãe [...] é por obrigação. $(E 6, E 7, E 9)$

[... I por livre e espontânea vontade não é. Tem horas que eu me sinto obrigada a cuidar dele. (E8)

No momento em Que a mãe adoece, os filhos vêem-se com a obrigação de retribuir o amor, os cuidados e tudo o Que foi feito por ela para sua família. Nesse momento, os cuidadores amparam suas falas no dever sociocultural de cuidar da mãe $e^{(6)}$.

As concepções de sociedade, status ou papel referem-se às relações das pessoas umas com as outras. QualQuer sociedade humana é composta por pessoas Que se engajam, Que interagem entre si. Nesse movimento interacionista, cada pessoa representa um papel Que envolve normas e valores sociais ${ }^{(8)}$.

Nesta perspectiva, ser pai, mãe, ou esposa, são papéis de grande significado para o individuo e família. A mulher, portanto, assume a tarefa de cuidar do marido como um compromisso nesse depoimento:

[...] é minha obrigação. Nem Que a gente num goste [...] além dele ser pai dos meus filhos. Tem Que cuidar [...] (E4)

Nessa situação a mulher demonstra não só o próprio papel dentro do grupo, mas também o do marido. Ele é o pai dos filhos dela, portanto, há uma regra social Que deve ser cumprida. Ele tem Que ser cuidado, pois pertence ao seu grupo familiar e representa o pai, aQuele que gera e oferece subsídios para a sobrevivência dos filhos.

\section{O Cuidado por Amor}

Porque eu amo, porque eu gosto, porque eu quero que ela fique bem. (EI)

[...] sempre que eu tô dando o banho dela eu digo que ela é o amor da minha vida [... Eu sabia Que no fim da vida dela eu tinha Que tá ao lado dela [...] (E9).

O sentimento de amor pela mãe, nos dois relatos, remete aos laços Que são construídos dentro de uma família. Eles explicam o desejo dos familiares nos domicílios visitados de estar próximos e de se cuidar mutuamente. $\mathrm{O}$ amor Que sentem uns pelos outros transformou a situação de adoecimento em oportunidade de aprendizado para a família.

Sabe-se Que o afeto entre o sujeito Que cuida e o familiar é essencial, porém não garante a competência para o cuidado. Apenas a experiência do cuidador, principalmente daQuele sem formação específica na área, não é suficiente para um cuidado efetivo. Dessa forma, fica explícita a necessidade de apoio e de orientação aos familiares Que cuidam com amor e assim tornam possível a recuperação e o tratamento de seus parentes no domicílio ${ }^{(13)}$.

\section{Percebendo o Familiar Vitimado pelo AVE}

São apresentadas as impressões relatadas pelos cuidadores acerca das incapacidades de seus familiares geradas pela doença. Dentre as incapacidades observadas pela pesquisadora durante as visitas domiciliárias, citam-se déficits motores e sensitivos, dificuldades na articulação da palavra, déficit de linguagem, apraxias e agnosias, redução do nível de consciência, hemiparesias e hemiplegias.

A maneira como os cuidadores percebiam esses fenômenos foi assim relatada:

[...] na minha concepção a minha mãe ia melhorar, ia ficar como ela era [...] ela não era doente. Ela só tinha as limitações dela [...] doente ela é agora que não dá conta de nada Que acontece. (C9) 
[...] de repente paralisou um lado, fica completamente imóvel, paralisa todo, não tem movimento nenhum e a comunicação ficou difícil [...] (C6).

Está explícito nas falas dos cuidadores o sentimento de pesar pelo grau de incapacidade de seus familiares, Que há pouco tempo não dependiam parcial ou totalmente de um cuidador. No momento da verbalização dessa dependência, o cuidador demonstrava inQuietação e confusão acerca do Que fazer ou sobre como cuidar.

A percepção das incapacidades biofisiológicas das vítimas de AVE não recebeu o mesmo destaque pelos cuidadores como a percepção da dependência do familiar. As deficiências fisiológicas eram referidas pelos cuidadores Quando expunham o apoio Que recebiam do PAD para aprender a manipular o material de curativos, os cateteres e drenos ou mesmo a dieta caseira preparada para aqueles familiares com gastrostomias.

Percebeu-se, portanto, Que o fenômeno da dependência dos familiares com relação à realização de atividades de vida diária gerava grande ineuietação e provocava alterações no ritmo de vida dos cuidadores. Esse foi o significado atribuído por eles diante da percepção das deficiências dos familiares.

\section{As Atividades Diárias dos Cuidadores}

Apresentam-se as atividades realizadas nos domicílios cotidianamente pelos cuidadores. Os cuidados subdividiram-se em atividades da vida diária (AVDs), como a alimentação, a integridade cutânea, a higiene, as eliminações, a terapêutica, a locomoção e a movimentação do ser cuidado, e as atividades instrumentais da vida diária (AIVDs) do cuidador, como preparar as refeições, lavar e passar as roupas, limpar a casa e realizar tarefas extradomiciliares.

Independente de haver divisão de tarefas com outros elementos da família, os cuidadores relataram a dificuldade e o cansaço físico gerados a partir do cuidado contínuo nas 24 horas diárias.

O estudo acerca da sobrecarga de cuidado Que o acidente cerebrovascular acarreta para as famílias mostra Que ela se relaciona com o nível de dependência física do portador da doença, o isolamento social do cuidador, as mudanças e insatisfações conjugais, as dificuldades financeiras geradas pelo abandono do emprego após a doença e os déficits na saúde física e no autocuidado do cuidador $^{(14)}$.

As AVDs ocupam grande espaço na vida cotidiana dos cuidadores e dos familiares por eles cuidados. Apesar dessa constatação, atentase para o fenômeno de Que cuidar do familiar não se restringe a ter cuidados com sua saúde. As atividades domésticas também fazem parte do mundo de vida dos cuidadores. Fala-se em atividades como ir ao supermercado ou à farmácia e cuidar da casa. Para os sujeitos Que cuidam sem Que haja divisão de tarefas, essa realidade é marcante nos depoimentos:

[... I não é muito fácil a vida Que eu tenho, é muito difícil.[...] eu tenho Que varrer casa, eu tenho que lavar banheiro, eu tenho Que fazer comida, eu tenho Que cuidar dele, eu tenho Que resolver as coisas de mercantil, eu tenho que resolver as coisas fora [...] Quando eu vou resolver minhas coisas, já é lá pra trás, fica mais adiante. $(C 5, C 8)$

Como se observa, as AIVDs estão presentes na rotina de cuidados, dão suporte à dinâmica das famílias e preenchem os dias dos cuidadores. São atividades necessárias para que o ambiente domiciliar mantenha-se em ordem para proporcionar ao familiar condições de ser higienizado e de se alimentar em Quantidade e horários corretos.

\section{Percebendo-se Cuidador}

Reúnem-se as características dos cuidadores, segundo suas próprias impressões. Eles falaram como se percebem diante do desafio de cuidar integralmente de um familiar incapacitado e Quais os sentimentos Que emergem na relação entre cuidador e ser cuidado.

Trata-se do conceito interacionista - self. O indivíduo elabora uma definição ou um conceito sobre si mesmo. Esse fenômeno sofre influência da percepção de outras pessoas a respeito de Quem é o cuidador ${ }^{(8)}$.

Alguns cuidadores acreditavam ser capazes de desenvolver Quaiseuer atividades de cuidado, sem sofrimento ou dificuldade:

Eu tenho o prazer de fazer o que eu faço, apesar do cansaço. Eu me sinto orgulhosa do que eu faço. Quando eu tenho uma coisa pra resolver que eu me saio vitoriosa, eu tenho prazer. (C7, C8, C9).

Paralelo à sobrecarga de trabalho, um segundo e fundamental aspecto para um "bom cuidador" é a vontade de cuidar. Os significados atribuídos por cada cuidador para o ato de cuidar de um familiar incapacitado depende do seu contexto de vida, ou seja, das histórias que fizeram parte de seu desenvolvimento como pessoa e Que despertaram sentimentos norteadores de seus comportamentos $^{(8,14)}$.

Apresentam-se, a seguir, respostas distintas de outros cuidadores para as mesmas condições de cuidado, ou seja, cuidar no domicílio, não ter formação técnica, ser membro da família e cuidar de pessoa incapacitada por AVC:

\section{Às vezes eu me sinto assim uma incapaz. (CI)}

\section{[...] eu Queria mais paciência e mais amor em mim [...] Queria} ter mais e mais pra dar $[\ldots](C 3, C 4, C 6)$.

Os sentimentos de satisfação e de prazer cedem lugar na discussão para a impotência, a impaciência, a insegurança, a angústia e até mesmo para a culpa. Sentir-se incapaz para cuidar exprime o fato de o cuidador não enxergar possibilidades de recuperação da autonomia de seu familiar.

Diante dos significados Que atribuíam aos seus comportamentos nas situações de estresse, os cuidadores chegavam a demonstrar sentimentos de culpa e se dirigiam à religião em busca de perdão:

\section{[... um pai. [...] eu cuido dela como se ela fosse minha filha [...] (C2)}

Nesse caso não se trata de um filho que cuida do pai, mas de um homem que precisa cuidar de sua sogra e o faz transferindo para ela os sentimentos de um pai para seus filhos. A dependência originada pelo AVE transforma a visão do cuidador acerca do seu 
papel diante do familiar, culminando em associar os seus cuidados aos de um pai com uma criança.

Indubitavelmente esse comportamento deriva das significações de dependência construídas ao longo dos anos de interação social pelo cuidador. Ele faz parte de um contexto social Que o ajudou a elaborar seus significados diante dos fenômenos, e os atos sociais derivados desse processo são coerentes com os valores e as crenças apreendidas.

\section{Transformações nas Vidas dos Cuidadores}

A construção de significados pelo homem é um processo interpretativo Que resulta em ação, pois, ao enfrentar o mundo Que o cerca, ele é chamado a agir, ou seja, a enfrentar as situações com as Quais se depara. Para chegar a tal intento, ele reflete, faz interpretações e determina sua ação à luz de suas reflexões ${ }^{(8)}$.

Isso significa Que situações como tornar-se cuidador, ter um familiar dependente de seus cuidados e assumir tarefas Que antes não conhecia afetam diretamente o cotidiano de um indivíduo. Inconscientemente, ele analisa a situação e fornece respostas a ela. Tudo Que ele venha a aprender representa mudança. Ocorrem alterações em sua rotina de vida e nos conteúdos com os Quais deve lidar cotidianamente.

As implicações impostas à vida do sujeito Que cuida são retratadas nessa categoria. Foram elencadas as transformações ocorridas na vida do cuidador a partir de seus relatos e das observações realizadas no domicílio:

[...] eu era uma pessoa ativa num outro sentido, porque Quando eu não tava trabalhando, eu tava lendo e essa atividade agora eu não consigo fazer [...] (CI).

[...] ia pra igreja, tinha reunião e tinha os grupos, eu não fui mais. [...] $O$ Que mais me tirou foi da minha vida Que eu tinha na igreja. (C9)

Retratam-se alterações na realização de atividades rotineiras pelo cuidador. São tarefas antes realizadas com freqüência e que traziam bem-estar para Quem as praticava. Além dos compromissos com o emprego ou com os cuidados da família, o ser humano também necessita preocupar-se com seu lazer e divertimento. São essas as atividades mais atingidas, uma vez que os familiares incapacitados requerem, em grande parte, cuidados nas vinte e Quatro horas diárias, fato Que dificulta a existência de momentos de relaxamento para o cuidador.

As significações acerca de si mesmo, incluídos os papéis Que desempenha no núcleo familiar e na sociedade, passam por um processo de ressignificação. A partir dos significados atribuídos por ele ao cuidado e às pessoas Que cuidam, ele estabelece um novo papel para si. Analisa o Que está aprendendo e fazendo para indicar a si mesmo Quem é e o Que faz.

Essas mudanças são marcantes para o cuidador e chegam inesperadamente, por isso requerem tempo para a adaptação dos sujeitos. Os mecanismos ou estratégias elaboradas pelos cuidadores representam sua sobrevivência diante da situação Que se apresenta em suas vidas, de repente. Com o passar do tempo, eles vão adQuirindo prática no seu fazer, sabedoria para enfrentar a situação sem sobressaltos e, ao final desse processo, conseguem relaxar um pouco e extrair lições para suas vidas a partir do vivido.

\section{CONSIDERAÇÕES FINAIS}

A aproximação com a singularidade dos cuidadores permitiu o conhecimento de seu "mundo de vida" e proporcionou a reflexão sobre a prática clínica do enfermeiro na situação de assistir a família Que necessita de reestruturação para receber o ente Querido incapacitado na residência.

As dificuldades demonstradas pelos cuidadores refletiram o grande déficit no tocante à orientação das famílias, no momento em Que o paciente recebe alta hospitalar. É a situação na Qual surgem as dúvidas e as inquietações acerca dos cuidados Que serão exigidos no domicílio, e a assistência do PAD, verdadeiramente, mostra-se necessária.

A enfermagem necessita valer-se de instrumentos de cuidado Que facilitem o processo de adaptação da família à nova situação. Destacam-se, então, a criatividade e a sensibilidade do profissional para promover a capacitação dos cuidadores Que irão colaborar diretamente com a equipe de saúde para possibilitar a continuidade dos cuidados extra-hospitalares.

Os resultados do estudo mostraram que o processo de acompanhamento dos cuidadores pelos profissionais do PAD é uma necessidade que se estende por um grande período e que requer, além de insumos materiais, habilidades dos profissionais para lidarem com seres humanos em sofrimento.

Os cuidadores familiares são reconhecidos como parceiros importantes no cuidado, pois são os elos de comunicação com os demais membros familiares. É por meio dessa comunicação Que as dúvidas são expostas e os problemas decorrentes da inexperiência da família com a nova situação apresentada são conhecidos.

Aos enfermeiros fica o desafio de elaborar estratégias de aproximação com essas pessoas. A sugestão Que se pode apresentar é a formação de grupos de apoio aos cuidadores e o fortalecimento dos Que já existem. Isso significa construir espaços para o diálogo, a exposição de dificuldades, o esclarecimento de dúvidas e a prática do acolhimento.

\section{REFERÊNCIAS}

1. Ministério da Saúde (BR). Programas e projetos: doenças cardiovasculares. Brasília: Ministério da Saúde; 2007.

2. Organização Panamericana de Saúde. Indicadores básicos de saúde no Brasil: conceitos e aplicações. Brasília: OPAS; 2002.

3. Organização Mundial da Saúde. Promovendo qualidade de vida após acidente vascular cerebral: um guia para fisioterapeutas e profissionais de atenção primária à saúde. Porto Alegre: Artmed; 2003.

4. Massaro AR. Acidente vascular cerebral isquêmico. In: Koizumi MS, Diccini S, organizadoras. Enfermagem em neurociência: fundamentos para a prática clínica. São Paulo: Atheneu; 2006. p. $329-48$. 
5. Perlini NMO, Faro ACM. Cuidar de pessoa incapacitada por AVC no domicílio: o fazer do cuidador familiar. Rev Esc Enferm USP 2005; 39(2): 154-63.

6. Lavinsky AE, Vieira TT. Processo de cuidar de idosos com acidente vascular encefálico: sentimentos dos familiares envolvidos. Acta Scient Health Scien 2004; 26(1): 41-5.

7. Bocchi SCM, Angelo M. Interação cuidador familiar-pessoa com AVC: autonomia compartilhada. Ciência e Saúde Coletiva 2005; I0(3): 729-38.

8. Blumer H. Symbolic interacionism: perspective and method. Berkley: University of California Press; 1969.

9. Charon IM. Symbolic interacionism: an introduction, an interpretation, an integration. Englewood Cliffts: Prentice-Hall; 1989.
10. Mead GH. Mind, self and society. Chigaco: University of Chigaco Press; 1934.

I I. Kawasaki D, Diogo MJD. Assistência domiciliária ao idoso: perfil do cuidador formal - Parte I. Rev Esc Enferm USP 200 I; 35(3): 257-64.

12. Bardin L. Análise de conteúdo. Lisboa: Edições 70; 1977.

13. Ministério da Saúde (BR). Conselho Nacional de Saúde. Comitê Nacional de Ética em Pesquisa em Seres Humanos. Resolução 196 de 10 de outubro de 1996: diretrizes e normas regulamentadoras de pesquisa envolvendo seres humanos. Brasília: Ministério da Saúde; 1996.

14. Bocchi SCM. Vivenciando a sobrecarga ao vir-a-ser um cuidador familiar de pessoa com acidente vascular cerebral (avc): uma análise do conhecimento. Rev Latino-am Enfermagem 2004; 12(1): 115-21. 